\title{
Spatial Distribution and Accessibility of Health Facilities in Akwa Ibom State, Nigeria. ${ }^{*}$ *Atser Jacob and ${ }^{*}$ Akpan P A
}

\begin{abstract}
Halting the spread of preventable diseases is one of the Millennium Development Goals (MDGs) with 2015 as target period for achievement. The attainment of this goal is a function of the spatial pattern of distribution of healthcare facilities and a measure of the degree of accessibility to healthcare services. This paper therefore analyzed the spatial patterns of healthcare facilities in Akwa Ibom State against the philosophy of achieving the MDGs in the health sector. Data from official records of government establishments were obtained while field observation in 50 rural communities was carried out using spatial sampling framework. Data on six health indicator variables were obtained and analyzed to assess the levels of access to healthcare facilities. The result depicts a lopsided distributional pattern of healthcare facilities and thus hinders good access to high quality healthcare services in the state. The paper concludes that the regional trend of development in the health sector is at variance with the subscription of the MDGs and the target achievement period of 2015 seems to be an illusion unless there is an aggressive intervention measures on the part of government.
\end{abstract}

Key words: Accessibility, Health Facilities, Akwa Ibom, Nigeria, Overview

\section{Introduction}

$\mathrm{I}$ n Nigeria, much concern has been focused on providing the basic needs of the people as a strategy to reduce the level of poverty in the society, hence the concern for the spatial patterns of distribution of the basic development needs that affect the wellbeing of the people. This concern derived greater inspiration from the level of the United Nations (UN) through the setting of 2015 as target period for achieving the Millennium Development Goals (MDGs) (UN 2000). The MDGs were developed in the year 2000 during a global convention with 187 countries including Nigeria in attendance to fashion out ways of achieving realistic development by providing those basic needs that would reduce poverty in society (UN 2000, World Bank 2002). In Nigeria, the health sector is one area where much concern is directed. This is because a healthy population is a prosperous one as it influences the level of productivity in all ramifications. According to welfare economic theory, equity in the distribution of basic development needs is indicative of the degree of accessibility of population to such services and facilities. Thus, knowledge on the nature of distribution of health care facilities is expedient in understanding the level of success or otherwise of health care delivery system in any society. In Akwa Ibom State as it is in most parts of the country, there is the dual problem of inadequate facilities and high level of poverty which with resultant low personal mobility, constrained access to health care facilities. It is therefore imperative to examine the spatial distribution of health care facilities in rural areas of Akwa Ibom State. Against this background, this study examined various issues in the health sector with a view to measure the degree of equitability in the distribution of health care facilities in rural areas of Akwa Ibom State.

\section{The Study Area}

Akwa Ibom State is the study area. It is one of the oil rich states in the Niger Delta Region of Nigeria. Located in the southeastern coast of Nigeria, Akwa Ibom State was created on September 23, 1987 from the former Cross River State of Nigeria. The State is wedged in between Rivers, Abia and Cross river States and the Republic of Cameroon to the Southwest, North, East and Southeast respectively while the Bight of Bonny bordered the State to the South. It lies between latitudes $4^{\circ} 32^{\prime}$ and $5^{\circ} 32^{\prime}$ North of the Equator, and longitudes $7^{\circ} 28^{\prime}$ and $8^{\circ} 25^{\prime}$ East of the Greenwich Meridian. According to NPC (1998), Akwa Ibom State has a total land area of $6,187 \mathrm{~km}^{2}$, which represents $0.67 \%$ of the total land mass of Nigeria. The State has 31 Local Government Areas with Uyo, Eket, Ikot Ekpene, Abak, Etinan, Ikot Abasi and Oron being the most developed urban centres. According to the 2006 National Population Census result, Akwa Ibom State had a total population of 3,920,208 persons out of which 87.89 percent constitutes rural population while 12.11 percent forms the urban population (NPC2007). The most striking characteristic of the population of Akwa Ibom State is its crude density. When compared with other states in the south-south and southeast,

** Department of Urban \& Regional Planning, University of Uyo. Nigeria jacobatser@yahoo.com

* Department of Geography/Regional Planning, University of Uyo,Nigeria 
the region is one of most densely settled state. In fact, apart from Imo and Anambra States, Akwa Ibom State is the most densely populated state with densities as high as 634 persons per square kilometer in Nigeria (NPC 2007). Thus, the spatial distribution of population in Akwa Ibom State makes it justifiable to examine the distributional pattern and accessibility levels of health facilities in rural areas where majority of the people is found.

\section{Method of the study}

Data on the number of health care facilities in all the 31 Local Government Areas in the state were obtained from the State Ministry of Health. Other relevant information on health matters such as existing national and international standards for measuring accessibility levels to health care services were obtained from official records of government establishments. To assess the levels of accessibility to health care facilities in the rural areas, field observations were conducted in 50 spatially sampled rural villages in the state. Spatial sampling framework was employed and a political map of the state was divided into 480 quadrates (grid cells). The use of quadrates as units of observations is not new. Abiodun (1981) used quadrates as units of observations in analysis of industrial growth patterns in Nigeria from 1962 to 1974 and had valid conclusions. To sample the villages, a table of random numbers was applied and 50 out of 480 spatial units were selected. In all the sampled villages, data on the types, number and ownership of health care facilities as well as number of hospital beds, doctors, nurses and distance to nearest health care facilities were obtained and analyzed using an index evolved specifically for this study. Descriptive statistics were used in the analysis and discussion of the result.

\section{Health sector overview in Nigeria}

In the health sector, much concern has been expressed pertaining to the pattern of distribution of heath care facilities and level of utilization. According to Inyang (1994), distributive equity in heath care facilities indexes accessibility. In other words, the level of access to health care facilities is a function of the degree of fairness in spatial distribution of the facilities. According to Smith (1987), inequality in facilities distribution is of crucial significance particularly in developing societies with dual problems of limited facilities and low personal mobility. Accessibility in this context has spatial theme and signifies the ease with which potential health care seekers get to points (health facilities) where health care services are delivered. The past National Development Plans in Nigeria have reflected the problems of equitable distribution of health care facilities in the country while regional studies by Ayoade (1982) and Inyang (1994) have confirmed the existence of inequality in the distribution of health care facilities.

The national health policy is aimed to achieve health for all Nigerians based on the national philosophy of social justice and equity as clearly enunciated in the second National Development Plan (1970-1974). These principles of social justice and equity and the ideals of freedom and opportunity have been affirmed in Nigeria's constitution. Thus, the national health policy was formulated in the context of these national objectives and philosophy. To this end, the primary health care was adopted as the means of achieving the national goal of social justice and equity in the health sector. As defined in Alma-Ata Declaration of 1978, primary health care facilities are intended to bring health care as close as possible to where people live and work (Egwu1996). The primary health care is therefore focused on rural dwellers. Inyang (1994) observed that the problem is not so much on the quality of services rendered but on adequacy of health facilities provided. The quality of services rendered is related to the level of manpower available. Although, WHO asserted that Nigeria is yet to develop a health manpower plan that describes the categories and number of personnel required taking into account current status (Egwu1996), the health manpower level in Nigeria appears impressive as shown in Table 1. Nigeria has exceeded the WHO standard for the African region (Table 2) of one doctor per 10,000 Population (Egwu 1996). However, the doctors are maldistributed, most of them being in the urban areas and in the southern states. While there are communities that have never seen a doctor, others have a ratio of one doctor to 200,000 Population (Sorungbe 1991). In terms of nurses, there are 5 times more nurses than doctors. Like the doctors, nurses are also maldistributed. However, many rural health centres throughout the country are manned by 
nurses who provide health care services to the rural populace (Egwu 1996).

From a study done by the Directorate of Food, Roads and Rural Infrastructure in 1987, Nigeria had about 100,000 villages and autonomous communities but there were about 10,711 health establishments at the primary health care level including health and maternity centres, health clinics and dispensaries (Sorungbe 1991). This means that there was roughly one facility per every 10 villages/communities and this made accessibility to health services very poor especially in rural areas. It is established that in health care services, patients are not prepared to travel more than $5 \mathrm{~km}$ or a half-hour journey on foot to receive health care services (FGN1991). Sorungbe (1991) further stressed that for preventive services such as immunization and health education, the distance people want to travel to receive services is much less than $5 \mathrm{kms}$ or half hour journey. Table 3 provides information on the threshold requirements in health care services delivery. These threshold requirements provide the basis for analyzing the pattern of health care facilities distribution among the 50 sampled communities in Akwa Ibom State.

\section{The Result}

In general, it is observed that Akwa Ibom State has a total of 286 health facilities spread across the 31 Local Government Areas as shown in Table 4. The distribution of health care facilities in the state is not even. The disparity in facility provision is observed among the 31 local government areas. For instance, 15 local government areas (41.94\%) have no general hospitals whereas Abak, Essien Udium and Etim Ekpo had two each while Etinan has three general hospitals. Uyo Local Government Area has a teaching hospital. The number of primary health centres among the 31 LGAs further demonstrated the persistence of inequalities in health care facilities distribution in the state. Thus, the disparity in the distribution of health facilities could generate corresponding disparities in the access the population has to health care. Thus, both tables 4 and 5 have revealed the level of existing disparity in the distribution of health care facilities in Akwa Ibom State.

From table 5, a standard deviation of 3.9 and 56.4 from the mean of 9.1 and 22.0 is observed among the LGAs and types of facilities. Skewness and kurtosis statistics are measures of normality of distribution. Thus, the absence of a perfect normality leads to the existence of skewness in a set of data. The effect of skewness is that the mode, mean and median in a set of data will have different values. The differences in the values of the measures of central tendency are indicative of the varying degrees of the distribution of health care facilities in Akwa Ibom State. From table 5, it is vivid that stronger disparity occurs in terms of facility types in the study area. The quality of services rendered is directly related to the hierarchy of healthcare facilities. Consequently, disparity in the distribution of high order healthcare facilities will result in corresponding disparities in access to good quality services. This problem is related to the issues of costs in terms of money, time and distances that must be overcome in order to access high quality services due to poor proximity to high order healthcare facilities. This implies that majority of the rural poor may resort to patronizing quacks or traditional health institutions with their adverse multiplier effects. Further investigations of the degrees of accessibility to health care facilities were carried out in 50 rural communities. Table 6 provides information on health care services in each of the 50 sampled rural communities using six health indicator variables to examine the level of access of the rural areas in respect of health care services A total of 30 health care facilities were enumerated during field surveys out of which 2 were general hospitals, 10 health centres and 12 health clinics while dispensary facilities were 6. However, a total of 20 sampled communities (40\%) had no health care facility of any kind despite their population thresholds for health clinics. Of the total number of health care facilities enumerated during the field survey, government ownership status stood at 30 percent. A total of 18 health facilities $(60 \%)$ were privately owned while $3(10 \%)$ were owned by the community/mission. Altogether, a total of 27 Doctors and 71 Nurses as well as 49 hospital beds were found among the health care facilities. Further investigation suggests that some communities have improved access to health facilities while others suffer poor access to health care facilities. For instance, the National policy on health provides for the 
establishment of at least one comprehensive health centre $(\mathrm{CHC})$ and four primary health however, investigations revealed that only 8 $\mathrm{CHC}$ are established in the state.

Another perspective from which health care facilities distribution is examined is the index values of the various communities studied. As shown in Table6, 21 communities (42\%) have index value of one (1) and above while 13 communities have index values, which indicate poorer access to health care service delivery. This result implies that only 21 communities had improved level of access to health care services. In this sense, inequality in the level of health care facilities distribution illustrated (Fig.1) On the whole; communities with index values less than one are disadvantaged communities while those with index values above one are advantaged areas. These findings are in accord with the findings of Inyang $(1992,1994)$ who pointed out that health care facilities in Akwa Ibom State are inequitably distributed among the local government areas. Thus, variation in levels of access to basic healthcare services in the study area occurs at both macro and micro levels.

From the preceding analysis on access to health care facilities, it may be safe to centres (PHC) in each local government area,

conclude that the rural areas are yet to have adequate access to health care services in the study area. The government decimal role in health care services is observed in the study area as exemplified by its $30 \%$ ownership status of all the health care facilities enumerated during the survey. The private sector is observed as the dominant player in the aspect of health care services provision in the study area. This sector is too sensitive to be controlled by the private sector with its profit driven motives. Generally, some communities have more than their fair share in terms of type of facility being provided. For instance, higher order facilities such as general hospitals and health centres were observed in communities with threshold requirements for health clinics and dispensaries whereas some communities with higher threshold requirements have no facility of any kind and as such, create deteriorating conditions in some communities than others. On the whole, the overall performance in this sector is fair, as only 20 (40\%) communities attained the minimum requirements.

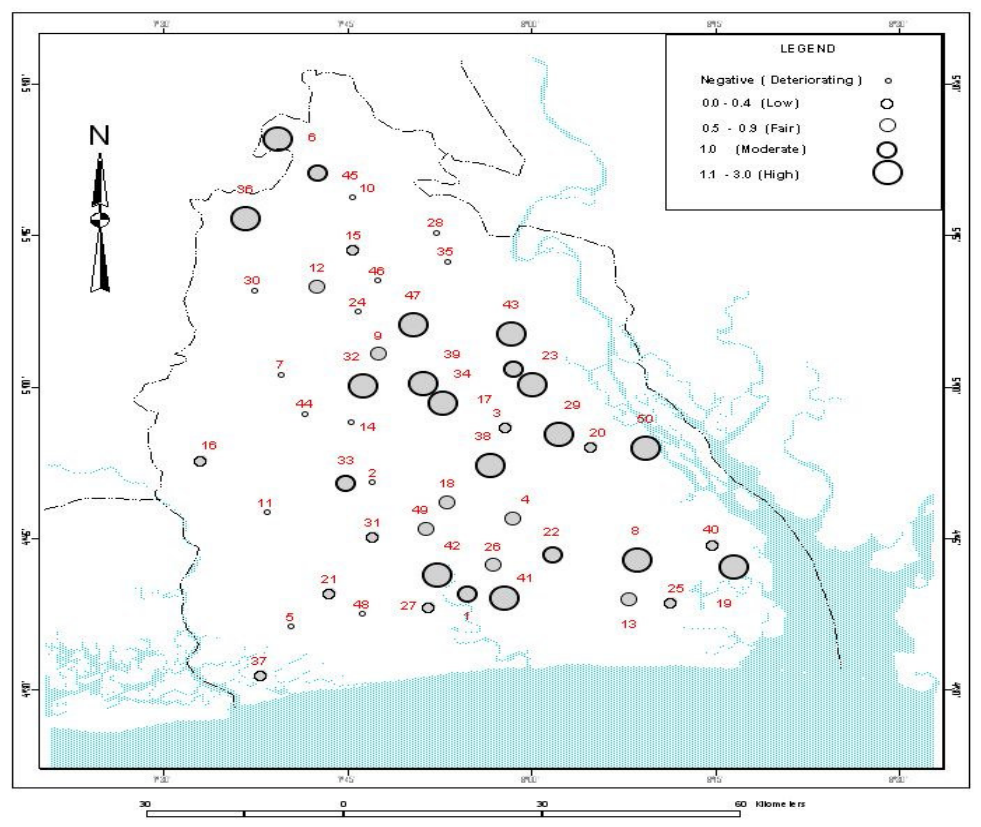

Fig. 4.3: Levels of Access of Health Care Facilities 


\section{Implications of the Result}

The Millennium Development Goals (MDGs) are the most recent attempts at improving the standards of living especially in developing societies. According to NISER (2003), most of the indictors of the millennium development goals are not likely to be achieved by the target date of 2015 in Nigeria. The result of this study has further supported this claim. The observed deficiency in the distribution of healthcare facilities in the study area is counter productive towards poverty alleviation. Given that there is high level of poverty among the people in this part of the world (Atser 2008) and considering the fact that poverty is seen as a multidimensional problem whose definition also emphasizes social dimensions (Duranlean 1995, European Commission 1993), the problem of poverty becomes very worrisome when viewed from the perspective of access to healthcare facilities. This implies that both inequality and poverty are characteristics of the study area. Because, inequality presents a unique form of poverty (Sanusi 2007) through mass deprivation, it is emphasized that the provision of healthcare facilities would ensure that growth is consistent with poverty reduction, a topical issue in the 2000 MDGs. In other words, the poor can be identified as those who are unable to have access to good quality healthcare services while the rich are those who have adequate access to the basic healthcare services for sustainable living.

Historically, poverty has been concentrated in rural areas. The result of this study implies that poverty is still prevalent in the rural areas of Akwa Ibom State. The $4^{\text {th }}$ NDP noted that

\section{References}

Abiodun J.O.1981. Aspects of the Spatial Impact of Development Efforts: A Case Study of Nigeria. TESG, 72 (2) pp 274-279.

Atser J 2008. Analysis of Spatial Patterns of Social Infrastructure in Rural Areas of Akwa Ibom State, Nigeria. Ph.D Thesis(Unpublished), Uyo: University of Uyo. Ayoade A 1982. The State and the Provision of health Facilities in Plateau State. Research for Development, NISER.

Duranlean D 1995. Poverty: Culture as a response. The courier, No 151 May-June. rural health care facilities generally are inadequate. This is confirmed in the results of this study. Some communities did not have any health care facility. Besides, most of the existing health care facilities were inadequate in terms of medical personnel (Doctors and Nurses). It is held that the ratio of population to infrastructure in most developing countries is far below the WHO standard for health care services coverage in both personnel and space (Inyang 1998). For the $3^{\text {rd }}$ world countries including Nigeria, the doctor/population ratio of 1:10,000 with mean hospital service range of $0-16 \mathrm{~km}$ radius is recommended (Egwu, 1996). The health sector assessment conducted for USAID/Nigeria in 1991 confirmed the extremely low level of health care provision in Nigeria. The existing inequality of access to health care facilities among the communities studied may generate corresponding disparities in levels of productivity among individuals and communities. This is as a result of the existing correlation between health status of population and productivity. Against the background of the implications of the result of this study, there is need for all the three tiers of government (local, state and federal) to play more active role towards the achievement of the MDGs in the health sector. From the study, some communities have been identified as vulnerable in terms of their poor access to healthcare services. The public and private sectors interventions should focus attention on the vulnerable or disadvantaged communities. In this context, the provision of facilities should be based on needs with population threshold serving as determinant factor.

Egwu I N 1996. Primary Health Care System in Nigeria: Theory, Practice and Perspectives. Elmore Printing \& Publishing Co; Lagos.

European Commission 1993. Developing Countries' Policies on Poverty \& Their Shortcomings. Luxembourg, European Commission.

FGN1991. Nigeria Health Profile. Federal Ministry of Health and Social Services(FMOH and SS), Lagos. 
ILO 1999. Global trends in Health. Report on terms of employment and working conditions in health sector reforms. ILO sectoral activities programme, Geneva.

Inyang I B 1994. Provision of Health Care Facilities in Nigeria: The Problem of Equity and Accessibility. Ibom Journal of Social Issues Vol. 1(2) pp. 78-91.

Inyang I B 1998. The Health Care Environment of Uyo Metropolis. Some Issues in Accessibility. In: Ukpong IE(Ed) Geography and the Nigerian Environment. NGA Book of Readings, pp 124-130.

NISER 2003. Millennium Development Goals: Nigeria's First Progress Report. NISER, Ibadan.

NPC 2007. 2006 National Population Census Result: Legal Notice on the Details of the Breakdown of the National and State Provisional Totals. Printed and published by the Federal Government Printer, Lagos, Nigeria. FGP71/52007/2500(OL24)
Sorungbe A O 1991. Strengthening the National and State Primary Healthcare Capacity. In: Ransomekuti O Sorumgbe A O Oyegbite K S and Banisaiye A (Eds.), Strengthening Primary Health Care at LGA level. Lagos, FMOH, pp. 1-16.

Sanusi YA 2007. Inequity in Environmental welfare in Nigerian urban centres: A case study of Minna. NITP Vol. XX (1) pp. 87-98.

Smith D 1987. Geography, Inequality and Society. Cambridge University Press, Cambridge.

World Bank 2005. World Development Report: Equity and Development. The World Bank, Washington D.C.

World Bank 2002. Reaching the Rural Poor-A Renewed Strategy for Rural Development. The World Bank, Washington DC.

UN 2000. Millennium Development Goals (MDGs)

http//www:sovereignty.net/p/gov/made.html

Table 1: Health Manpower per Population in Nigeria

\begin{tabular}{|l|c|c|}
\hline Table 1: Health Manpower per Population in Nigeria \\
\hline Personnel & Total Number & Number/100,000 \\
\hline Doctors & 20,210 & 22.8 \\
\hline Dentists & 1197 & 1.35 \\
\hline Pharmacists & 6060 & 6.8 \\
\hline Nurses & 71712 & 81.0 \\
\hline Midwives & 68036 & 65.5 \\
\hline
\end{tabular}

Source: FGN (1991)

Table 2 Health Personnel and Infrastructure, 1988-92

\begin{tabular}{|l|c|c|c|}
\hline & Doctor/1000 pop & Nurses/doctor & Hospital beds/1000pop \\
\hline Sub-Saharan Africa & 0.12 & 5.1 & 1.4 \\
\hline India & 0.41 & 1.1 & 0.7 \\
\hline China & 1.37 & 0.5 & 2.6 \\
\hline Other Asian & 0.3 & 3.0 & 1.8 \\
\hline Latin America & 1.25 & 0.5 & 2.7 \\
\hline Formerly Socialist Countries & 4.07 & 2.2 & 11.4 \\
\hline
\end{tabular}

Source: ILO (1999)

Table 3 Threshold Requirements in the Health Sector

\begin{tabular}{|l|c|c|c|}
\hline \multicolumn{1}{|c|}{ Type of Facility } & Population & Beds/10,000 & Service Radius \\
\hline Teaching Hospital & Entire state & 1.5 & Entire State \\
\hline General Hospital & 150,000 & 4.0 & $80 \mathrm{~km}$ \\
\hline Health centre & 20,000 & 3.0 & $24 \mathrm{~km}$ \\
\hline Health clinic & 2,000 & 2.0 & $5 \mathrm{~km}$ \\
\hline
\end{tabular}

Sources: FGN(1991)

Tale 5: Descriptive statistics of the distribution of Healthcare Facilities

\begin{tabular}{|l|l|l|}
\hline Parameters & By LGA & By Types \\
\hline Mean & 9.193548387 & 22 \\
\hline Mode & 7 & 8 \\
\hline Standard Error & .702406547 & 15.54919821 \\
\hline Standard Deviation & 3.910834138 & 56.42399017 \\
\hline Sample Variance & 15.2946 & 3183.666 \\
\hline Kurtosis & .004072206 & 12.7221888 \\
\hline Skewness &. .434482089 & 3.552835975 \\
\hline Minimum & 1 & 1 \\
\hline Maximum & 18 & 208 \\
\hline Sum & 286 & 286 \\
\hline
\end{tabular}


Table 4 Distribution of Health facilities in Akwa Ibom State (2006)

\begin{tabular}{|c|c|c|c|c|c|c|c|c|c|c|c|c|c|c|c|}
\hline L G A & $\begin{array}{l}\text { Populati } \\
\text { on }\end{array}$ & MH & GH & $\mathbf{C H}$ & $\mathbf{P H}$ & IDH & LH & WH & DH & CHC & PHC & SC & HP & $\mathbf{C}$ & Total \\
\hline Abak & 139090 & 1 & 1 & - & - & - & 1 & - & - & - & 9 & - & - & - & 12 \\
\hline Eastern Obollo & 60543 & - & - & - & - & - & - & - & - & - & 4 & - & - & - & 4 \\
\hline Eket & 172557 & 1 & - & - & 1 & - & - & - & 1 & 1 & 6 & - & - & - & 10 \\
\hline Essien Udim & 192668 & 1 & 1 & - & - & - & - & - & - & - & 9 & - & 4 & - & 14 \\
\hline Etim Ekpo & 105118 & 1 & 1 & - & - & - & - & - & - & - & 10 & - & - & - & 12 \\
\hline Etinan & 169284 & 1 & 2 & - & - & - & 1 & - & - & 1 & 9 & - & 4 & - & 18 \\
\hline Esit Eket & 63701 & - & - & 1 & - & - & - & - & - & - & 6 & - & - & - & 7 \\
\hline Ibesikpo Asutan & 137101 & - & - & - & - & - & - & - & - & - & 1 & - & - & - & 1 \\
\hline Ibeno & 75380 & - & - & - & - & - & - & - & - & - & 5 & - & - & - & 5 \\
\hline Ibiono Ibom & 189640 & 1 & - & - & - & - & - & - & - & - & 16 & - & - & - & 17 \\
\hline Ika & 72939 & - & - & - & - & 1 & - & - & - & - & 5 & 1 & - & - & 7 \\
\hline Ikono & 131904 & - & 1 & - & - & - & - & - & - & - & 8 & - & - & - & 9 \\
\hline Ikot Abasi & 132023 & - & 1 & - & - & - & - & - & - & 1 & 6 & - & - & - & 8 \\
\hline Ikot Ekpene & 143077 & - & 1 & - & - & 1 & 1 & 1 & - & - & 3 & - & 6 & 2 & 15 \\
\hline Ini & 99196 & - & 1 & - & - & - & - & - & - & - & 9 & - & - & - & 10 \\
\hline Itu & 127033 & - & 1 & - & - & - & 1 & - & - & - & 5 & - & - & - & 7 \\
\hline Mbo & 104012 & - & - & - & - & - & - & - & - & - & 8 & - & - & - & 8 \\
\hline Mkpat Enin & 178036 & - & - & 3 & - & - & - & - & - & - & 8 & - & - & - & 11 \\
\hline Nsit Atai & 74595 & - & - & - & - & 1 & - & - & - & 1 & 4 & - & - & - & 6 \\
\hline Nsit Ibom & 108611 & - & - & - & - & - & - & - & - & - & 10 & 1 & - & - & 11 \\
\hline Nsit Ubium & 128231 & - & - & 2 & - & - & - & - & - & 1 & 6 & - & - & - & 9 \\
\hline Obot Akara & 148281 & - & - & - & - & - & - & - & - & 1 & 4 & - & - & - & 5 \\
\hline Okobo & 104057 & - & 1 & - & - & - & - & - & - & - & 5 & - & - & - & 6 \\
\hline Onna & 123373 & - & - & 1 & - & - & 1 & - & - & 1 & 9 & - & - & - & 12 \\
\hline Oron & 87461 & - & 1 & - & - & - & - & - & - & - & 5 & - & - & - & 6 \\
\hline Oruk Anam & 172654 & - & 1 & 1 & - & - & - & - & - & - & 10 & - & 3 & - & 15 \\
\hline Udung Uko & 53278 & - & - & - & - & - & - & - & - & - & 8 & - & - & - & 8 \\
\hline Ukanafun & 127033 & - & - & - & - & - & 1 & - & - & - & 6 & - & - & - & 7 \\
\hline Uruan & 118300 & - & 1 & - & - & - & 1 & - & - & 1 & 5 & - & - & - & 8 \\
\hline Urue Offong & 71159 & - & 1 & - & - & - & - & - & - & - & 5 & - & - & - & 6 \\
\hline \multirow[t]{2}{*}{ Uyo } & 309573 & 1 & 1 & - & - & - & - & - & 1 & - & 5 & 3 & - & - & 11 \\
\hline & Total & 7 & 16 & 8 & 1 & 3 & 7 & 1 & 2 & 8 & 209 & 5 & 17 & 2 & 286 \\
\hline
\end{tabular}

Source: Akwa Ibom State Ministry of Health Headquarters, Uyo (2006). GH- General hospital ,CH -Cottage Hospital, PH- Psychiatric Hosp, IDHInfectious Disease Hosp. LP- Leprosy Hosp, WH-Welfare Hosp. DC-Dental Centre, CHC- Comp.Health Centre, PHC- Primary Health centre, SC-Staff Clinic, HP- Health Post, CH- Children Home, MH- Missionary Hosp. 


\begin{tabular}{|c|c|c|c|c|c|c|c|c|c|c|c|c|c|c|c|c|c|c|c|c|c|c|}
\hline & \multicolumn{4}{|c|}{$\mathbf{A}$} & \multicolumn{4}{|c|}{ B } & \multicolumn{4}{|c|}{$\begin{array}{ll}\mathbf{C} \\
\end{array}$} & D & \multicolumn{4}{|c|}{$\mathbf{E}$} & \multicolumn{4}{|c|}{$\mathbf{F}$} & \multirow[t]{2}{*}{ Index } \\
\hline & O & e & d & $\mathbf{L}_{1}$ & $\mathbf{0}$ & $\mathbf{E}$ & d & $\mathbf{L}_{2}$ & O & $\mathbf{E}$ & d & $\mathbf{L}_{3}$ & $\mathbf{L}_{4}$ & 0 & e & d & $\mathbf{L}_{5}$ & O & e & d & $\mathbf{L}_{6}$ & \\
\hline 1 & 2 & 2 & 0 & 1.0 & 1 & 0.50 & 0.50 & 2.0 & 2 & 1.8 & 0.2 & 1.1 & 1 & 1 & 0.8 & 0.2 & 1.3 & 11.0 & 5 & -6.0 & \begin{tabular}{c|}
-0.2 \\
\end{tabular} & 1.03 \\
\hline 2 & 0 & 2 & -2 & 0 & 0 & 0.73 & -0.73 & 0 & 0 & 2.6 & 2.6 & 0 & 0 & 0 & 1.0 & -1.0 & 0 & 15.1 & 5 & -10.1 & -1.02 & -0.17 \\
\hline 3 & 2 & 2 & 0 & 1.0 & 0 & 0.67 & -0.67 & 0 & 1 & 2.4 & -1.4 & 0.4 & 1 & 0 & 0.9 & -0.9 & 0 & 8.5 & 5 & -3.5 & 0.3 & 0.45 \\
\hline 4 & 2 & 2 & 0 & 1.0 & 0 & 1.16 & -1.16 & 0 & 2 & 4.1 & \begin{tabular}{|l|}
-2.1 \\
\end{tabular} & 0.5 & 1 & 0 & 1.5 & -1.5 & 0 & 6.5 & 5 & $\begin{array}{l}-1.5 \\
\end{array}$ & 0.7 & 0.53 \\
\hline 5 & 0 & 2 & -2 & 0 & 0 & 0.52 & -0.52 & 0 & 0 & 1.9 & -1.9 & 0 & 0 & 0 & 0.7 & -0.7 & 0 & 15.3 & 5 & -10.3 & -1.1 & -0.18 \\
\hline 6 & 3 & 2 & 1 & 1.5 & 1 & 1.07 & -0.07 & 0.9 & 3 & 3.8 & -0.8 & 0.8 & 3 & 2 & 1.9 & $\begin{array}{l}0.1 \\
\end{array}$ & 1.1 & 12.5 & 5 & $\begin{array}{l}-7.5 \\
\end{array}$ & -0.5 & 1.13 \\
\hline 7 & 0 & 1 & -1 & 0 & 0 & 0.44 & -0.44 & 0 & 0 & 1.6 & -1.6 & 0 & 0 & 0 & 0.4 & -0.4 & 0 & 9.5 & 3 & -6.5 & -1.2 & -0.20 \\
\hline 8 & 3 & 2 & 1 & 1.5 & 0 & 0.79 & -0.79 & 0 & 3 & 2.8 & 0.2 & 1.1 & 3 & 2 & 1.4 & 0.6 & 1.4 & 2.5 & 5 & 2.5 & 1.5 & 1.42 \\
\hline 9 & 1 & 1 & 0 & 1.0 & 0 & 0.43 & -0.43 & 0 & 1 & 1.5 & -0.5 & 0.6 & 1 & 1 & 0.4 & 0.6 & 2.5 & 10.0 & 3 & -7.0 & -1.4 & 0.61 \\
\hline 10 & 0 & 1 & -1 & 0 & 0 & 0.34 & -0.34 & 0 & 0 & 1.2 & $\begin{array}{l}-1.2 \\
\end{array}$ & 0 & 0 & 0 & 0.3 & $\begin{array}{l}-0.3 \\
\end{array}$ & 0 & 13.5 & 3 & -10.5 & -2.5 & -0.42 \\
\hline 11 & 0 & 2 & -2 & 0 & 0 & 0.58 & -0.58 & 0 & 0 & 2.1 & -2.1 & 0 & 0 & 0 & 0.8 & -0.8 & 0 & 11.5 & 5 & -6.5 & -0.3 & -0.05 \\
\hline 12 & 2 & 2 & 0 & 1.0 & 1 & 0.96 & $\begin{array}{l}0.04 \\
\end{array}$ & 1.0 & 2 & 3.4 & -1.4 & 0.6 & 1 & 0 & 1.3 & \begin{tabular}{|l|}
-1.3 \\
\end{tabular} & 0 & 7.5 & 5 & -2.5 & 0.5 & 0.68 \\
\hline 13 & 2 & 2 & 0 & 1.0 & 1 & 2.80 & -1.80 & 0.4 & 3 & $\begin{array}{l}9.9 \\
\end{array}$ & -6.9 & 0.3 & 1 & 2 & 3.8 & -1.8 & 0.5 & 5.0 & 5 & 0 & 1.0 & 0.70 \\
\hline 14 & 0 & 1 & -1 & 0 & 0 & 0.18 & -0.18 & 0 & 0 & 0.6 & -0.6 & 0 & 0 & 0 & 0.3 & -0.3 & 0 & 7.5 & 3 & -4.5 & -0.5 & -0.08 \\
\hline 15 & 1 & 1 & 0 & 1.0 & 0 & 0.20 & -0.20 & 0 & 0 & 0.7 & -0.7 & 0 & 1 & 0 & 0.3 & -0.3 & 0 & 7.5 & 3 & -4.5 & -0.5 & 0.25 \\
\hline 16 & 0 & 2 & -2 & 0 & 0 & 0.73 & \begin{tabular}{|c|}
-0.73 \\
\end{tabular} & 0 & 0 & 2.6 & -2.6 & 0 & 0 & 0 & 1.0 & -1.0 & 0 & 5.5 & 5 & $\begin{array}{l}-0.5 \\
\end{array}$ & $\begin{array}{l}1.1 \\
\end{array}$ & 0.18 \\
\hline 17 & 2 & 2 & 0 & 1.0 & 1 & 1.23 & -0.23 & 0.8 & 3 & 4.4 & -1.4 & 0.7 & 1 & 2 & 1.6 & 0.4 & 1.3 & 2.0 & 5 & 3.0 & 1.6 & 1.07 \\
\hline 18 & 1 & 1 & 0 & 1.0 & 0 & 0.18 & -0.18 & 0 & 1 & 0.6 & 0.4 & 1.6 & 1 & 0 & 0.2 & -0.2 & 0 & 1.5 & 3 & 1.5 & 0.5 & 0.68 \\
\hline 19 & 3 & 2 & 1 & 1.5 & 1 & 0.99 & 0.01 & 1.0 & 4 & 3.5 & 0.5 & 1.1 & 1 & 4 & 1.8 & 2.2 & 2.2 & 6.0 & 5 & -1.0 & 0.8 & 1.27 \\
\hline 20 & 0 & 2 & -2 & 0 & 0 & 2.41 & -2.41 & 0 & 0 & 8.6 & -8.6 & 0 & 0 & 0 & 3.2 & -3.2 & 0 & 9.5 & 5 & -4.5 & 0.1 & 0.02 \\
\hline 21 & 0 & 2 & -2 & 0 & 0 & 2.36 & -2.36 & 0 & 0 & 8.4 & $\begin{array}{l}-8.4 \\
\end{array}$ & 0 & 0 & 0 & 3.1 & $\begin{array}{l}-3.1 \\
\end{array}$ & 0 & 8.5 & 5 & -3.5 & 0.3 & 0.05 \\
\hline 22 & 3 & 2 & 1 & 1.5 & 1 & 1.59 & -0.59 & 0.6 & 2 & 5.7 & -3.7 & 0.4 & 3 & 2 & 2.8 & -0.8 & 0.7 & 8.4 & 5 & -3.4 & 0.3 & 1.08 \\
\hline 23 & 3 & 2 & 1 & 1.5 & 1 & 0.63 & 0.37 & 1.6 & 3 & 2.2 & 0.8 & 1.4 & 3 & 1 & 1.1 & -0.1 & 0.9 & 10.5 & 5 & -5.5 & -0.1 & 1.38 \\
\hline 24 & 0 & 1 & -1 & 0 & 0 & 0.24 & -0.24 & 0 & 0 & 0.9 & -0.9 & 0 & 0 & 0 & 0.2 & -0.2 & 0 & 12.0 & 3 & $\begin{array}{l}-9.0 \\
\end{array}$ & -2.0 & -0.33 \\
\hline 25 & 0 & 2 & -2 & 0 & 0 & 0.83 & \begin{tabular}{c|}
-0.83 \\
\end{tabular} & 0 & 0 & 2.9 & -2.9 & 0 & 0 & 0 & 1.8 & -1.8 & 0 & 7.5 & 5 & -2.5 & 0.5 & 0.08 \\
\hline 26 & 1 & 2 & -1 & 0.5 & 0 & 0.48 & -0.48 & 0 & 2 & 1.7 & 0.3 & 1.2 & 1 & 2 & 0.6 & 1.4 & 3.3 & 17.5 & 5 & -12.5 & -1.5 & 0.75 \\
\hline 27 & 0 & 2 & -2 & 0 & 0 & 0.88 & -0.88 & 0 & 0 & 3.1 & -3.1 & 0 & 0 & 0 & 1.2 & -1.2 & 0 & 3.0 & 5 & 2.0 & 1.4 & 0.23 \\
\hline 28 & 0 & 1 & -1 & 0 & 0 & 0.13 & -0.13 & 0 & 0 & 0.5 & -0.5 & 0 & 0 & 0 & 0.2 & -0.2 & 0 & 12.0 & 3 & -9.0 & -2.0 & -0.33 \\
\hline 29 & 4 & 2 & 2 & 2.0 & 2 & 1.61 & 0.39 & 1.2 & 5 & 5.7 & -0.7 & 0.9 & 2 & 4 & 3.5 & 0.5 & 1.1 & 5.0 & 5 & 0 & 1.0 & 1.37 \\
\hline 30 & 0 & 2 & -2 & 0 & 0 & 0.73 & -0.73 & 0 & 0 & 2.6 & -2.6 & 0 & 0 & 0 & 1.0 & $\begin{array}{l}-1.0 \\
\end{array}$ & 0 & 10.2 & 5 & -5.2 & 0.0 & -0.01 \\
\hline 31 & 0 & 2 & -2 & 0 & 0 & 0.60 & \begin{tabular}{c|}
-0.60 \\
\end{tabular} & 0 & 0 & 2.1 & -2.1 & 0 & 0 & 0 & 0.8 & \begin{tabular}{l|l}
-0.8 \\
\end{tabular} & 0 & 7.5 & 5 & -2.5 & 0.5 & 0.08 \\
\hline 32 & 2 & 1 & 1 & 2.0 & 1 & 0.38 & 0.62 & 2.6 & 2 & 1.4 & 0.6 & 1.4 & 1 & 1 & 0.5 & 0.5 & 2.0 & 6.5 & 3 & -3.5 & -0.2 & 1.46 \\
\hline 33 & 2 & 2 & 0 & 1.0 & 1 & 0.97 & 0.03 & 1.0 & 3 & 3.4 & $\begin{array}{l}-0.4 \\
\end{array}$ & 0.9 & 1 & 2 & 1.7 & 0.3 & 1.2 & 3.2 & 5 & 1.8 & 1.4 & 1.08 \\
\hline 34 & 3 & 2 & 1 & 1.5 & 1 & 0.48 & 0.52 & 2.1 & 4 & 1.7 & 2.3 & 2.4 & 3 & 3 & 0.8 & 2.2 & 3.8 & 4.2 & 5 & $\begin{array}{l}0.8 \\
\end{array}$ & 1.2 & 2.33 \\
\hline 35 & 0 & 1 & -1 & 0 & 0 & 0.39 & -0.39 & 0 & 0 & 1.4 & -1.4 & 0 & 0 & 0 & 0.3 & -0.3 & 0 & 8.8 & 3 & -5.8 & -0.9 & -0.15 \\
\hline 36 & 2 & 1 & 1 & 2.0 & 1 & 0.34 & 0.66 & 2.9 & 3 & 1.2 & 1.8 & 2.5 & 1 & 0 & 0.5 & -0.5 & 0 & 7.0 & 3 & -4.0 & $\begin{array}{l}-0.3 \\
\end{array}$ & 1.35 \\
\hline 37 & 1 & 1 & 0 & 1.0 & 0 & 0.26 & -0.26 & 0 & 0 & 0.5 & -0.5 & 0 & 1 & 0 & 0.2 & \begin{tabular}{c|}
-0.2 \\
\end{tabular} & 0 & 7.8 & 3 & $\begin{array}{l}-4.8 \\
\end{array}$ & -6.0 & 0.23 \\
\hline 38 & 2 & 2 & 0 & 1.0 & 1 & 0.64 & 0.36 & 1.5 & 2 & 2.3 & $\begin{array}{l}-0.3 \\
\end{array}$ & 0.9 & 2 & 2 & 1.1 & 0.9 & 1.8 & 10.1 & 5 & -5.1 & 0.0 & 1.20 \\
\hline 39 & 3 & 2 & 1 & 1.5 & 1 & 0.56 & 0.44 & 1.8 & 3 & 2.0 & 1.0 & 1.5 & 3 & 1 & 1.0 & 0 & 1.0 & 8.6 & 5 & -3.6 & 0.3 & 1.52 \\
\hline 40 & 0 & 1 & -1 & 0 & 0 & 0.19 & -0.19 & 0 & 0 & 0.7 & -0.7 & 0 & 0 & 0 & 0.3 & -0.3 & 0 & 6.8 & 5 & $\begin{array}{l}-1.8 \\
\end{array}$ & 0.6 & 0.10 \\
\hline 41 & 2 & 2 & 0 & 10 & 1 & 1.06 & -0.06 & 0.9 & 2 & 3.8 & -1.8 & 0.5 & 2 & 2 & 1.4 & 0.6 & 1.4 & 5.5 & 5 & -0.5 & 0.9 & 1.12 \\
\hline 42 & 3 & 2 & 1 & 1.5 & 2 & 1.03 & 0.97 & 1.9 & 4 & 3.7 & 0.3 & 1.1 & 3 & 2 & 1.8 & 0.2 & 1.1 & 11.5 & 5 & -6.5 & -0.3 & 1.38 \\
\hline 43 & 4 & 2 & 2 & 2.0 & 2 & 1.32 & 0.68 & 1.9 & 4 & 4.7 & -0.7 & 0.9 & 1 & 4 & 2.9 & 1.1 & 1.4 & 3.8 & 5 & 1.2 & 1.2 & 1.33 \\
\hline
\end{tabular}


Ethiopian Journal of Environmental Studies and Management Vol.2 No.2. 2009

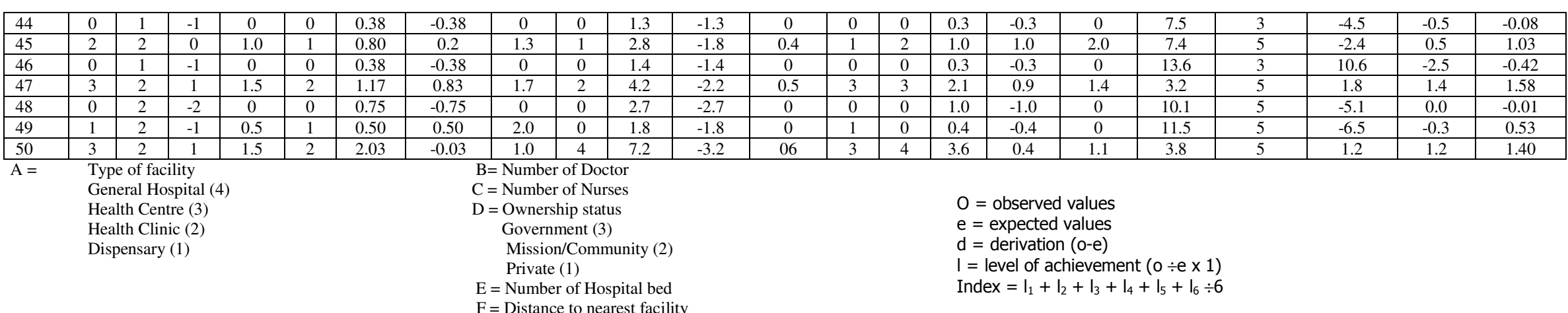

